\title{
Effect of Kale Cultivation Conditions on Biosynthesis of Xanthophylls
}

\author{
Magdalena Ligor ${ }^{1} \&$ Bogusław Buszewski ${ }^{1}$ \\ 1 Department of Environmental Chemistry and Bioanalytics, Faculty of Chemistry, Nicolaus Copernicus \\ University, Toruń, Poland \\ Correspondence: Magdalena Ligor, Chair of Environmental Chemistry and Bioanalytics, Faculty of Chemistry, \\ Nicolaus Copernicus University, 7 Gagarin St, PL 87100 Toruń, Poland. Tel: 48-566-114-836. E-mail: \\ mada@chem.umk.pl
}

Received: August 27, 2012 Accepted: September 7, 2012 Online Published: October 25, 2012

doi:10.5539/jfr.v1n4p74

URL: http://dx.doi.org/10.5539/jfr.v1n4p74

\begin{abstract}
Conditions of plant cultivation directly influence the chlorophyll and carotenoid pigments concentrations. The aim of investigations was the determination of lutein in kale (Brassica oleracea L. var. acephala) upon various cultivation conditions including: low and high temperature (overnight and daytime in the greenhouse the temperature was $12 \pm 2{ }^{\circ} \mathrm{C}$ and in the laboratory the temperature was $22 \pm 2{ }^{\circ} \mathrm{C}$ ), lack of water (some plants were watered only one time weekly), saline stress ( $5 \%$ of sodium chloride added to irrigation water; watering two times weekly was applied), as well as UV radiation of plants by means of UV lamp ( $\lambda=254 \mathrm{~nm}$; suitable to UVC solar radiation; duration $4 \mathrm{~h}$ per day). Three months old cuttings were taken and next mentioned cultivation conditions were applied during one month. Moreover, the outdoor cultivation of kale cuttings was performed. Qualitative and quantitative analyses of plant extracts were made by use of HPLC-UV-VIS-MS technique. Mean values for lutein accumulation as a function of dry mass $(\mathrm{mg} / \mathrm{g})$ in leaves of kale have been presented. Obtained results show maximum xantophylls (lutein) concentration occur in fully developed plant leaves of kale for red kale $2.04 \pm 0.15$ and green kale $1.10 \pm 0.09 \mathrm{mg} / \mathrm{g}$ respectively.
\end{abstract}

Keywords: lutein, kale, HPLC-UV-VIS, LC/MS

\section{Introduction}

One of the richest sources of carotenoids, especially xanthophylls, is plant material like kale. Kale (Brassica oleracea L. var. acephala) is one of the oldest cultivate form of cabbage. The central leaves are green or purple in color. It is considered to be closer to wild cabbage than most domesticated forms. The species it contains a wide array of vegetables including broccoli, cauliflower, collard greens, and brussels sprouts and they are similar genetically (Wood, 1988). Kale is considered to be a highly nutritious vegetable with powerful antioxidant properties and is anti-inflammatory. The concentration of vitamin $\mathrm{K}$, vitamin $\mathrm{C}$, lutein, zeaxanthin as well as $\beta$-carotene in kale is very high (Sikora et al., 2008). Also it is reasonably rich in calcium. The antioxidant activity of kale is higher than as follows garlic, spinach, brussel sprouts as well as broccoli flowers (Cao et al., 1996). More popular than kale, an edible and flowering green vegetables is spinach (Spinacia oleracea) (Wright, 2001). Leaves of this plant contain antioxidant flavonoids, in particular spinacetin and patuletin (Aehle et al., 2004). The biological activities of spinach polyphenols have been already reported (Edenharder et al., 2001; Gil et al., 1999; Lomnitski et al., 2000). Spinach as a vegetable is very important in daily diet. It is an important raw-material in the food processing industry (Aritomi \& Kawasaki, 1984; Gil et al., 1999). However kale is suitable vegetable to storing for a long period of time. Qualitative changes in kale leaves after preliminary processing and preservation by freezing were insignificant. Obtained results confirmed, that freezing was a better method of preserving kale leaves since the loss of nutritive constituents was lower than in the case of canning (Korus \& Lisiewska, 2011).

Nutrients including carotenoids are needed by human organism for the protection from cancer as well as against various diseases and fast grow old (Holden, 1999). All nutrients are assimilated only from daily diet rich of vegetables and fruits. Xanthophylls belong to the carotenoids. These compounds are also antioxidants like carotenoids (Rao \& Rao, 2007; Jackson et al., 2008). The group of xanthophylls includes lutein, zeaxanthin, neoxanthin, violaxanthin, and $\alpha$ - and $\beta$-cryptoxanthin. Their molecular structure is based on carotenes, with 
additional oxidation. One of important nutrients is lutein, a yellow plants pigment. In human health it plays an important role. Lutein is considered as very strong antioxidant, which can destroy free radicals. This is connected with the influence of lutein for the protection of eye and skin. High concentration of lutein can be found in retina, where it works as a filter from blue and UV light and as an antioxidant in the scavenging of photo-induced free radicals (Landrum \& Bone, 2001; Wood, 1988). It can be produced in high amount because of increased exposition of retina on light (Mozaffarieh et al., 2003). The similar protection (lutein as a filter), found in skin, reduces risk of skin cancer. Also lutein plays a protective role from cataract and AMD (Age-related Macular Degeneration). AMD is very problematic diseases, and high intake of lutein can reduce risk even about $50 \%$ (Wood, 1988). Its next important role is reducing a risk of cardiovascular diseases, as artherosclerosis, because it prevents oxidation of HDL (High Density Lipoprotein) to LDL (Low Density Lipoprotein) (Handelman et al., 1999; Loane et al., 2008; Ribaya-Mercado \& Blumberg, 2004; Roberts et al., 2009; Rock, 1997; Sommerburg et al., 1998; Tyssandier et al., 2002; Voutilainen et al., 2006).

From the analytical point of view, chlorophylls and carotenoids are most successfully analyzed by liquid chromatography (LC) and thin-layer chromatography (TLC) (Aman et al., 2005; Kurilich et al., 1999; Tsao et al., 2004; Lin et al., 2007; Quach et al., 2004). Modern analysis employs mass spectrometry techniques (MS) with electrospray (ESI), which have had the ability to elucidate complex analyties structures through the determination of accurate molecular weights and limited fragmentation patterns. The development of advanced methods of separation including HPLC as well as LC/MS has been observed especially in qualitative and quantitative analyses of carotenoids mixtures (Tsao et al., 2004).

In the current study, results of lutein and other pigments accumulations within kale leaves of plant cultivate in different cultivation conditions have been presented. Changes of pigments concentration were observed in various phases of plants growth. Various growth conditions like: low and high temperature, lack of water, saline stress by using of water contained $5 \%$ of sodium chloride, UV radiation $(\lambda=254 \mathrm{~nm})$ were applied. Mentioned conditions were applied during one month of all investigations. The comparison of obtained results for plant before start and in the end of experiments was made.

\section{Methods and Materials}

\subsection{Preparation of Kale Samples}

The kale cultivar under investigation was Winterbor $\mathrm{F}_{1}$ (green leaves) and Redbore $\mathrm{F}_{1}$ (red leaves), produced by the Dutch firm Bejo Zaden b.v. (Netherlands). These cultivars are classed among those most resistant to disease and frost damage. Our inestigation were carried out between Fabruary and October. Winterbor $F_{1}$ and Redbore $F_{1}$ kale varieties were planted from seeds with two plants in sterilized soil obtained from local market (OBI, Torun, Poland) per pot (14 cm diameter, $12 \mathrm{~cm}$ height) in a greenhouse. Plants were grown without supplemental light at ambient relative humidity for 12 weeks. Cuttings were germinated in a greenhouse, under natural lighting conditions. The three replications of each kale seedling were prepared. Any additional water-soluble fertilizer was not applied. Three months old plants were taken to investigations. During our investigations (four weeks) plants characterised by red and green leaves were cultivated still in greenhouse (ambient temperature $10-14^{\circ} \mathrm{C}$ ) and also in the laboratory (ambient temperature $20-24^{\circ} \mathrm{C}$ ). Various cultivation conditions were applied, such as: low and high temperature (overnight and daytime in the greenhouse the temperature was $12 \pm 2{ }^{\circ} \mathrm{C}$ and in the laboratory the temperature was $22 \pm 2^{\circ} \mathrm{C}$ ), lack of water (selected plants were watered only one time weekly), saline stress by adding $\mathrm{NaCl}$ to irrigation water $(5 \%$ solution of $\mathrm{NaCl})$. Effects of $\mathrm{UV}$ radiation $\lambda=254 \mathrm{~nm}$ were also checked. The applied radiation is suitable to UVC solar radiation. Selected plants cultivated in the laboratory were taken for this part of experiments. The ultraviolet lamp (COBRABID, Warsaw, Poland) was used in the continous mode during $4 \mathrm{~h}$ per day. All plants taken under cosideration (beside those for lack of water experiment), were watered three times per week. Simultaneously three cuttings of Winterbor $F_{1}$ and Redbore $F_{1}$ kale were cultivated in mentioned conditions. After one month experiments (after 16 weeks the seedlings were planted) harvest of plants was made.

Also, the outdoor cultivation of kale cuttings was performed. Kale was grown from seedlings planted in an experimental field located in northern Poland, on the western outskirts of Torun $\left(53^{\circ} \mathrm{N}, 18^{\circ} \mathrm{E}\right)$. Previously obtained seedlings were planted at spacings of $50 \times 50 \mathrm{~cm}$ in late June. The mineral fertilization was applied according to the fertility of soil and the nutritional requirements of the crop. Plants grew under natural lighting and temperature conditions. A single harvest was carried out 16 weeks after planting, during the one day of October. The main veins were then removed from the usable leaves (those with good colour and undamaged by disease or others). Fully developed plants were examined to compare the results. 
Air-drying was carried out using electric laboratory drier (power rating 1200W; Elektron, Warsaw, Poland). Cut kale leaves were dried at a temperature of $60^{\circ} \mathrm{C}$, this being the temperature of air blowing over the first lower sieve. The position of sieves was changed every $30 \mathrm{~min}$ to prevent crusting at the beginning of the drying process and roasting at the end. The drying time required to attain the redetermined humidity level of below $5 \%$ was $8 \mathrm{~h}$. After drying, samples were ground with a mortar (Christison, Gateshead, Tyne and Wear, United Kingdom) with pestle. Compounds contained in plant samples were extracted from the leaves by grinding with organic solvents ( $1 \mathrm{~mL}$ of methanol to $0.05 \mathrm{~g}$ of dried kale). The extraction was performed about 24 hours. Then extracts were filtered through a $0.2 \mu \mathrm{m}$ PTFE filter (Econofilter PTFE 25/20; Agilent Technologies, Wilmington, Germany) using a $10 \mathrm{~mL}$ syringe (Van Oostveen Medical B.V., Wilnis, The Nederlands). Finally we disposed of three extracts of Winterbor $F_{1}$ and Redbore $F_{1}$ kale, which were cultivated in various conditions. Obtained extracts were kept in a refrigerator $\left(4^{\circ} \mathrm{C}\right)$.

Next experiment occurred the assessment of carotenoids constituents in kale leaves by means of HPLC-UV-VIS-MS. The level of selected carotenoid concentration, namely lutein, formed the criterion for evaluation. The concentration of lutein in kale extracts before and after all experiments was compared. Scheme of sample preparation method used for separation of pigments from kale leaves is presented in Figure 1.

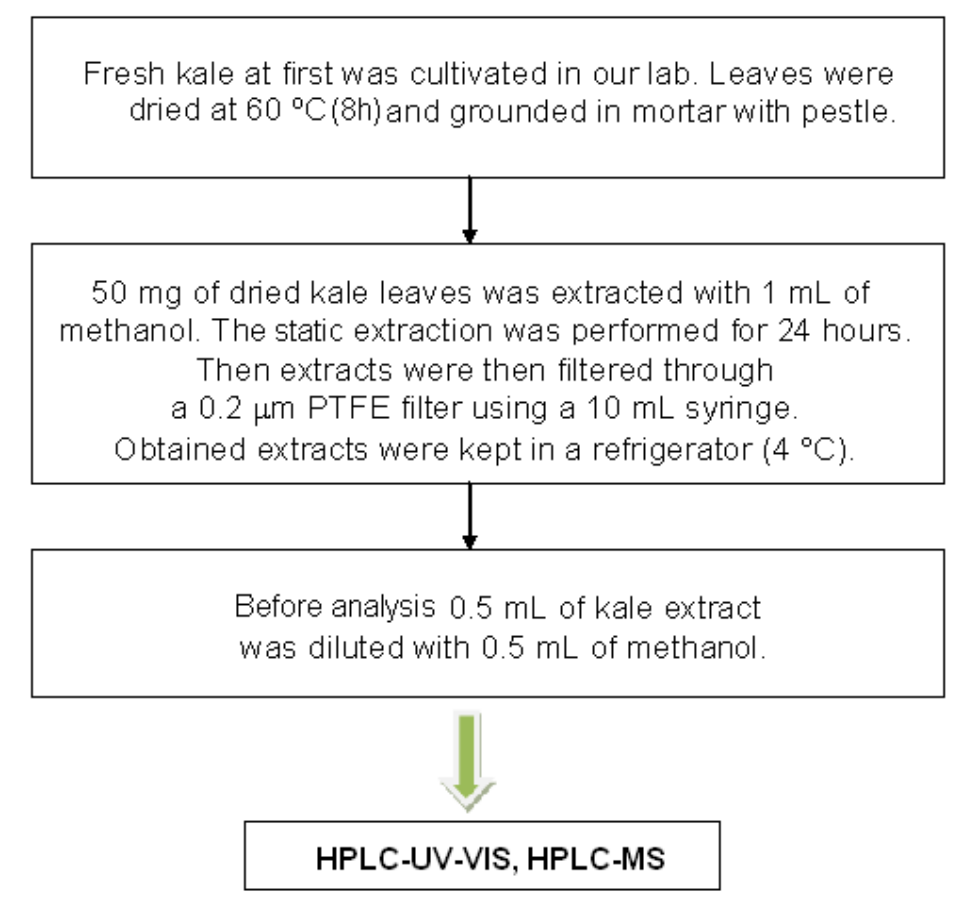

Figure 1. Scheme of sample preparation method used for separation of pigments from kale leaves

\subsection{Carotenoid Content - HPLC Analysis}

The HPLC unit with Agilent Quaternary Pump1100, coupled to UV-VIS detector and Triple Quad 6410 mass spectrometer (Agilent Technologies, Palo Alto, CA, USA) was used for pigment separation. All samples were analysed for lutein using a Zorbax C8 column, diameters: $150 \times 4.6 \mathrm{~mm} \mathrm{I.D;} \mathrm{d}_{\mathrm{p}}=5 \mu \mathrm{m}$ (Agilent Technologies). The column was maintained at $25^{\circ} \mathrm{C}$. HPLC effluent was simultaneously monitored by UV-VIS detector and MS Standard solutions and plant extracts were eluted at a flow rate of $1.0 \mathrm{~mL} / \mathrm{min}$ using a binary solvent system consisting of $\mathrm{A}$ : water/formic acid $(0.1 \%)$ and $\mathrm{B}$ : acetonitrile as a mobile phase. The gradient was performed as follows: from 0 to $5 \mathrm{~min}-50 \% \mathrm{~B}$, from 5 to $10 \mathrm{~min}-60 \% \mathrm{~B}$, from 10 to $15 \mathrm{~min}-70 \% \mathrm{~B}$, from 15 to $20 \mathrm{~min}-$ $80 \% \mathrm{~B}$, from 20 to $30 \mathrm{~min}-85 \% \mathrm{~B}$. The eluent was returned to $50 \% \mathrm{~A}$ and $50 \% \mathrm{~B}$ for $10 \mathrm{~min}$ to re-equlibrate the column prior to the next injection. Peak assignment was performed by comparing retention times and absorption obtained from the UV-VIS and MS detection of authentic standard (lutein from Carl Roth GmbH, Karlsruhe, Germany). Eluted compounds from a $10.0 \mu \mathrm{L}$ injection volume were detected at wave length $\lambda=450 \mathrm{~nm}$ by UV-VIS detector and simultaneously by mass spectrometer. Collected data were recorded and integrated using ChemStation Software (Agilent Technologies). 


\subsection{MS Conditions for Analyses}

Identification The HPLC unit with Triple Quad 6410 mass spectrometer was used. The ESI source at capillary voltage $4000 \mathrm{~V}$ and at temperature $325^{\circ} \mathrm{C}$ was applied. Nitrogen at flow rate $9 \mathrm{~L} / \mathrm{min}$ was used as drying gas. The spectrometer was operated in the positive ion mode. Mass spectra of lutein were acquired with full scan range $(\mathrm{m} / z 100-1000)$ and single ion monitoring - SIM $(\mathrm{m} / z 551$ and 568, fragmentor 150$)$.

Quantification For the calibration procedure standards mixtures of lutein (Carl Roth GmbH, Karlsruhe, Germany) in methanol (Sigma-Aldrich, St. Louis, MO, USA) were prepared. The concentration of lutein was in the range $1.60-50.00 \mu \mathrm{g} / \mathrm{mL}$. Kale extracts obtained from plants taken to investragations were also analysed.

\subsection{Method Validation}

All calibration data namely average of the peak retention time $\left(t_{R}\right)$, standard deviation (SD) estimated for $t_{R}$, calibration equations using peaks area for LC/MS and LC with UV detection, linearity presented as a correlation coefficient $\left(\mathrm{R}^{2}\right)$ of the calibration curves, limits of detection (LOD) and quantification (LOQ), precision (RSD) as a relative standard deviation estimated for peak areas are presented in Table 1.

\subsection{Statistical Analysis}

Statistical analysis allowing a comparison of the content of anti-oxidant compounds was carried out using single-factor analysis of variance (ANOVA) on the basis of the Snedecor F and Student's t tests, and the least significant difference (LSD) was calculated at the probability level $\mathrm{p}<0.01$. The Stastica 8.0 program (StatSoft, 2007) was used.

\section{Results}

In our investigations varieties of kale Winterbor1 (green leaves) and Redbor1 (red leaves) were taken into consideration. Representative LC/MS chromatograms of extracts obtained from leaves of green and red kale are presented in Figure 2. An electro spray ionisation (ESI) was applied for LC/MS analyses.

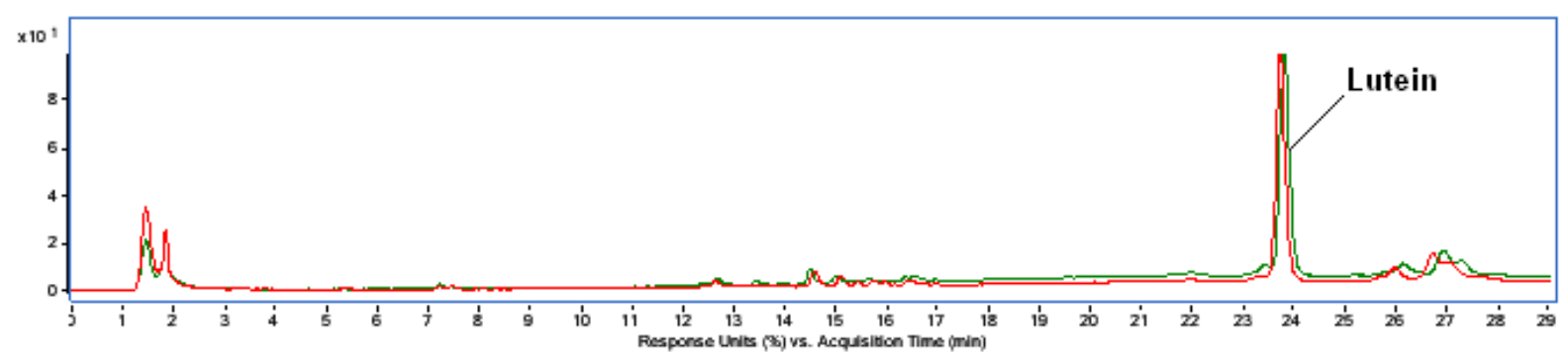

Figure 2. Comparison of chromatograms for red and green kale cultivated in ambient temperature $25^{\circ} \mathrm{C}$ (red line colour - red kale, green line colour - green kale). Detection UV, wavelength $\lambda=450 \mathrm{~nm}$

The comparison of LC/MS chromatograms obtained in full scan and single ion monitoring (SIM) modes are presented in Figure 3. 

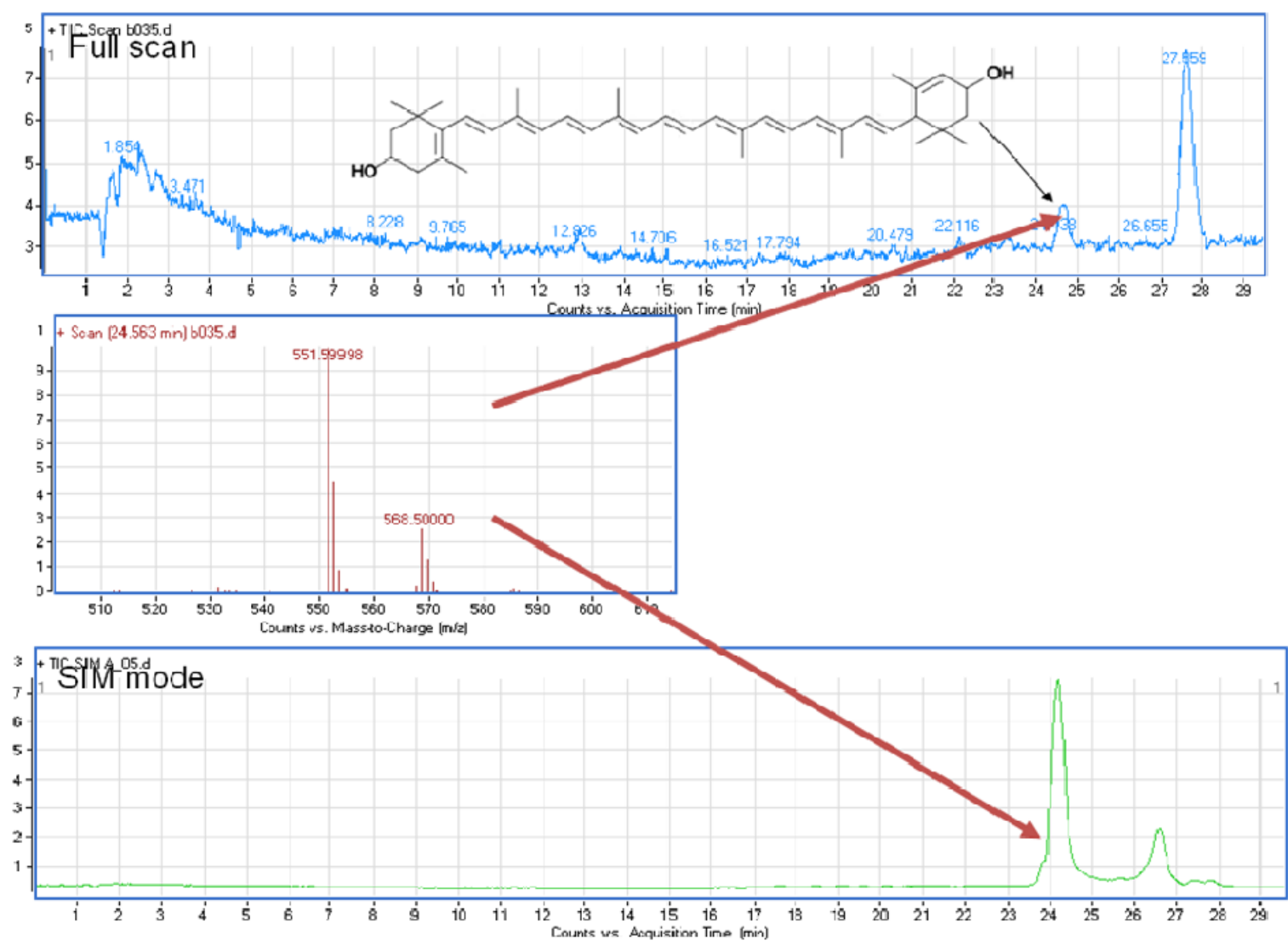

Figure 3. MS spectrum of lutein in full scan (A) and SIM (B) modes

Mass spectra of lutein acquired with a full scan range $m / z 100-1000$ and a single ion monitoring (SIM) $(\mathrm{m} / z$ 551 and 568) was targeted for study. Nevertheless, limit of detection evalueted for lutein (LOD $=0.20 \mu \mathrm{g} / \mathrm{mL}$ ) was lowest for a SIM mode than full scan mode. We desided to apply SIM mode for the qualitative and quantitative analyses of plant extracts and standard solutions.

Series of working solution containing standard of lutein at six concentration levels were obtained for the establishment by the linear least-squares regression procedure. The particular calibration data of standard mixture are listed in Table 1.

Table 1. Calibration data used for the determination of lutein in plant extracts by HPLC/MS

\begin{tabular}{lcccccccc}
\hline $\begin{array}{c}\text { Detection } \\
\text { method }\end{array}$ & $\begin{array}{c}\text { Retention } \\
\text { time }\left(\mathrm{t}_{\mathrm{R}}\right) \\
{[\mathrm{min} .]}\end{array}$ & $\begin{array}{c}\mathrm{SD} \\
\text { estimated } \\
\text { for } \mathrm{t}_{\mathrm{R}} \\
{[\mathrm{min} .]}\end{array}$ & $\begin{array}{c}\text { Concentration } \\
\text { range } \\
{[\mu \mathrm{g} / \mathrm{mL}]}\end{array}$ & $\begin{array}{c}\text { Calibration } \\
\text { curve }\end{array}$ & $\mathrm{R}^{2}$ & $\begin{array}{c}\mathrm{LOD} \\
{[\mu \mathrm{g} / \mathrm{mL}]}\end{array}$ & $\begin{array}{c}\text { LOQ } \\
{[\mu \mathrm{g} / \mathrm{mL}]}\end{array}$ & $\begin{array}{c}\mathrm{RSD} \\
\text { estimated } \\
\text { for peak } \\
\text { areas }[\%]\end{array}$ \\
\hline $\mathrm{MS}$ & 23.781 & 0.045 & $1.60-50.00$ & $\begin{array}{c}\mathrm{y}=1962.8 \\
\mathrm{x}+148.89\end{array}$ & 0.9969 & 0.20 & 0.60 & 5.64 \\
$\mathrm{UV}(\lambda=$ & 23.738 & 0.059 & $1.60-50.00$ & $\begin{array}{c}\mathrm{y}=4.4445 \\
\mathrm{x}-1.9406\end{array}$ & 0.9995 & 0.50 & 1.50 & 6.47 \\
$450 \mathrm{~nm})$ & & & & & & & & \\
\hline
\end{tabular}

The correlation coefficients $\left(\mathrm{R}^{2}\right)$ were calculated, higher than 0.9995 , confirming good linearity of the method. The solutions were each injected three times $(n=3)$. The reproducibility study was carried out by performing three parallel replicate extractions and analysis at the concentration of $10 \mu \mathrm{g} / \mathrm{mL}$ for lutein under the optimal conditions. The resultant reproducibilities expressed as relative standard deviations (RSDs) were 5.64\% 
estimated for peak areas of lutein by HPLC-MS and $6.47 \%$ estimated for peak areas of lutein by HPLC-UV-VIS. These results (see Table 1) show that the proposed method has a high sensitivity and reproducibility.

In analysis method of lutein solutions, sensitivity is evaluated by the assessment of the limit of detection (LOD) and limit of quantification (LOQ). The LOD and LOQ for the lutein with this method were defined as the content of the compound in extract (expressed as $\mu \mathrm{g} / \mathrm{mL}$ ) that gave rise to a signal-to-noise ratio of 3 and 6 within its retention-time window. The values of LOD and LOQ for the lutein were estimated at $0.60 \mu \mathrm{g} / \mathrm{mL}(\mathrm{MS})$ and $1.50 \mu \mathrm{g} / \mathrm{mL}$ (UV-VIS).

The quantitative analysis of compounds determined in plant extracts was done by the external standard method. Results of lutein concentration in leaves of kale cultivated in various conditions are presented in Figure 4.

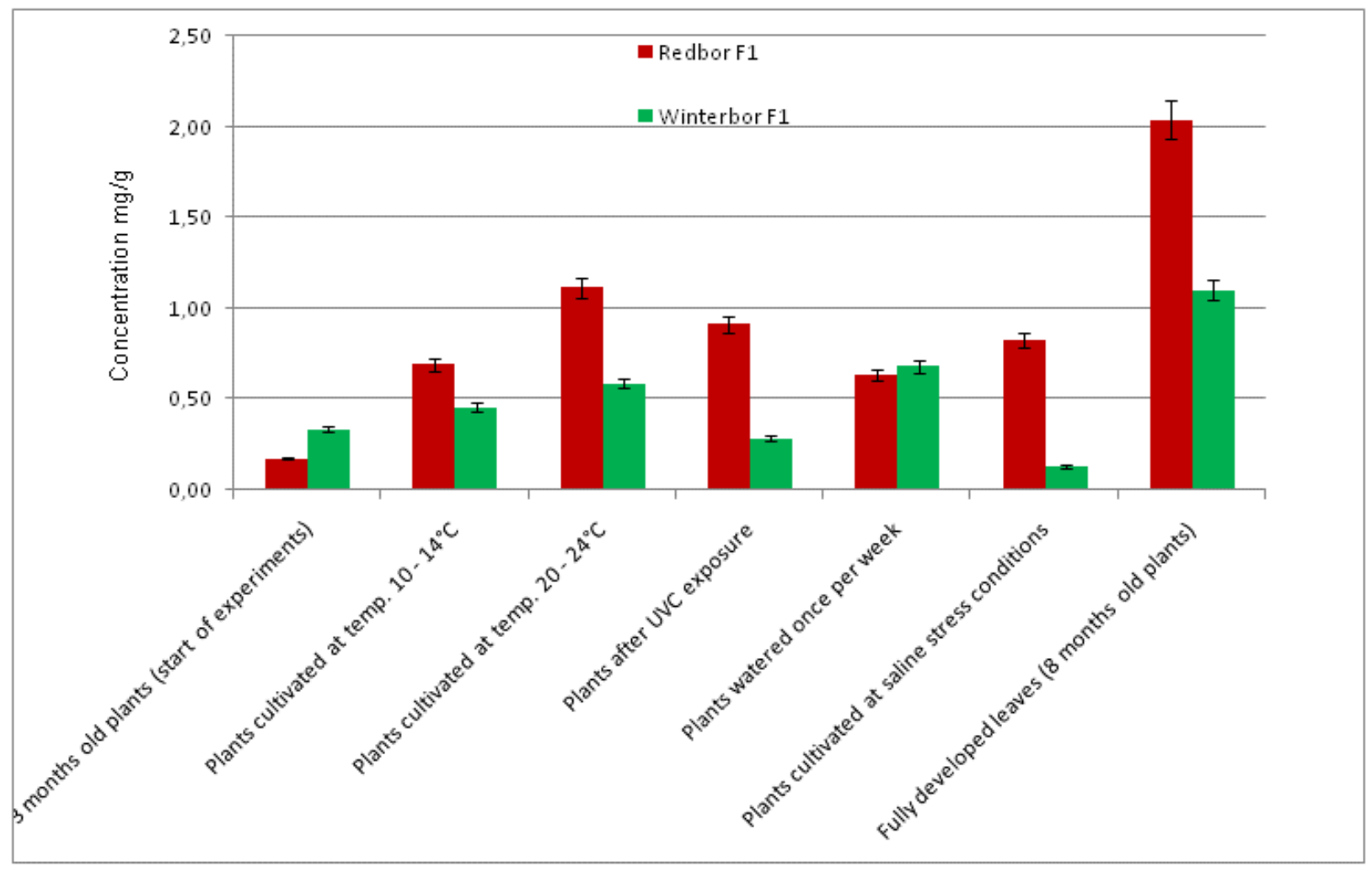

Figure 4. Results of lutein concentration in kale extracts by HPLC-MS

Obtained data allow for the determination of lutein in mg per $1 \mathrm{~g}$ of dry kale samples. Obtained results gives possibility to compare differences of lutein concentrations in leaves of various green vegetables. Table 2 shows quantities of lutein in red, green kale extracts by means of HPLC technique with MS detection. 
Table 2. Comparison of mean values for lutein accumulation as a function of dry mass (mg/g) in leaves of kale obtained by means of HPLC-UV-VIS and HPLC-MS ${ }^{\mathrm{a}}$

\begin{tabular}{|c|c|c|c|c|c|c|}
\hline \multirow{2}{*}{ Sample } & \multirow{2}{*}{$\begin{array}{c}\begin{array}{c}\text { Kale } \\
\text { cultivar }\end{array} \\
\text { Detection } \\
\text { system }\end{array}$} & \multicolumn{2}{|c|}{$\begin{array}{c}\text { Redbor } F_{1} \\
{[\mathrm{mg} / \mathrm{g}]}\end{array}$} & \multicolumn{2}{|c|}{$\begin{array}{c}\text { Winterbor } F_{1} \\
{[\mathrm{mg} / \mathrm{g}]}\end{array}$} & \multirow{2}{*}{$\begin{array}{c}\text { LSD } \\
\mathrm{p}<0.01\end{array}$} \\
\hline & & UV-VIS & MS & UV-VIS & MS & \\
\hline \multicolumn{2}{|c|}{$\begin{array}{l}3 \text { months old plants } \\
\text { (start of experiments) }\end{array}$} & $0.12 \pm 0.01$ & $\begin{array}{l}0.18 \pm \\
0.02\end{array}$ & $0.29 \pm 0.03$ & $\begin{array}{l}0.33 \pm \\
0.03\end{array}$ & 0.008 \\
\hline \multicolumn{2}{|c|}{$\begin{array}{l}\text { Plants cultivated at temp. } \\
10-14^{\circ} \mathrm{C} \text { during } 1 \\
\text { month }\end{array}$} & $0.70 \pm 0.06$ & $\begin{array}{c}0.69 \pm \\
0.05\end{array}$ & $0.42 \pm 0.04$ & $\begin{array}{c}0.46 \pm \\
0.04\end{array}$ & 0.020 \\
\hline \multicolumn{2}{|c|}{$\begin{array}{l}\text { Plants cultivated at temp. } \\
20-24^{\circ} \mathrm{C} \text { during } 1 \\
\text { month }\end{array}$} & $1.08 \pm 0.09$ & $\begin{array}{l}1.12 \pm \\
0.09\end{array}$ & $0.67 \pm 0.05$ & $\begin{array}{c}0.59 \pm \\
0.05\end{array}$ & 0.065 \\
\hline \multicolumn{2}{|c|}{$\begin{array}{l}\text { Plants after UVC } \\
\text { exposure during } \\
1 \text { month }\end{array}$} & $0.90 \pm 0.08$ & $\begin{array}{c}0.92 \pm \\
0.08\end{array}$ & $0.22 \pm 0.02$ & $\begin{array}{c}0.28 \pm \\
0.02\end{array}$ & 0.122 \\
\hline \multicolumn{2}{|c|}{$\begin{array}{l}\text { Plants watered once per } \\
\text { week during } 1 \text { month }\end{array}$} & $0.67 \pm 0.05$ & $\begin{array}{c}0.64 \pm \\
0.05\end{array}$ & $0.64 \pm 0.07$ & $\begin{array}{c}0.68 \pm \\
0.05\end{array}$ & 0.002 \\
\hline \multicolumn{2}{|c|}{$\begin{array}{l}\text { Plants cultivated at } \\
\text { saline stress conditions } \\
\text { during } 1 \text { month }\end{array}$} & $0.79 \pm 0.08$ & $\begin{array}{c}0.82 \pm \\
0.06\end{array}$ & $0.11 \pm 0.01$ & $\begin{array}{c}0.13 \pm \\
0.01\end{array}$ & 0.130 \\
\hline \multicolumn{2}{|c|}{$\begin{array}{l}\text { Fully developed leaves } \\
\text { (8 months old plants) }\end{array}$} & $1.94 \pm 0.12$ & $\begin{array}{c}2.04 \pm \\
0.15\end{array}$ & $0.98 \pm 0.02$ & $\begin{array}{c}1.10 \pm \\
0.09\end{array}$ & 0.258 \\
\hline
\end{tabular}

${ }^{a}$ Values are presented as mean value \pm SD $(n=9)$ and expressed in dry matter.

\section{Discussion}

Many genetic, biochemical as well as physiological factors influence the content and distribution of carotenoids in plants (Goldmann et al., 1999; Grusak et al., 1999). The physiological age of plant leaves and conditions of growth directly influence in chlorophyll and carotenoid pigments concentrations. The increased coloration in vegetable and fruit tissues associated with maturity is often indicative of increases in carotenoid concentrations (Kopsell et al., 2004; Lefsrud et al., 2005; Lefsrud et al., 2006; Lefsrud et al., 2007; Gross, 2001). It is still unclear, what changes the concentration of carotenoid in leaf during leaf ontogeny and various conditions during plant growth.

The air temperature significantly influences the growing effects of kale. This plant can grow under a wide range of air temperature, with optimum growth occurring at $20^{\circ} \mathrm{C}$ (Paul, 1991; Decoteau, 2000). We observed that the concentation of lutein in kale leaves is higher, when plants grow at high air temperature. We compare results for plants grow in cold green house (range of air temperature $10-14{ }^{\circ} \mathrm{C}$ ) and in the laboratory room (range of air temperature $20-24^{\circ} \mathrm{C}$ ). Maximum concentrations of lutein occur in kale leaves cultivated at high lab temperature. Particular data are as follow $1.12 \pm 0.09 \mathrm{mg} / \mathrm{g}(1.08 \pm 0.09 \mathrm{mg} / \mathrm{g}$ by UV-VIS detection) and $0.59 \pm 0.05 \mathrm{mg} / \mathrm{g}(0.67$ $\pm 0.05 \mathrm{mg} / \mathrm{g}$ by UV-VIS detection) for red and green kale respectively. These amounts are about $80 \%$ higher than in kale leaves of 3 months old plants (start of experiments). However, for plants cultivated at low temperature the concentration of lutein was on the same level $(0.69 \pm 0.05$ for red kale and $0.46 \pm 0.04 \mathrm{mg} / \mathrm{g}$ for green kale by MS detection). These amounts are about two times higher than in the beginning of experiments. Kale can grow successfully under a wide range of air temperature, but growth occurring between 20 and $25{ }^{\circ} \mathrm{C}$, brings better unfold leaves. Changes in the concentration of mentioned compound in kale leaves from the beginning to the end of experiments were explicit visible. For red kale the concentration of lutein was six times higher.

One of the most common environmental stresses for plants can be incoming solar radiation. On the other hand, the light is required to provide energy for plant metabolic systems. During light exposure of plant leaves surface, antenna pigmets absorb phothons and obtained energy is transfered to the photosynthetic reaction center (Lefsrud et al., 2006). In the reaction centre, molecules of chlorophylls, pheophytins, and quinones convert light 
energy into life process energy (Frank \& Cogdell, 1996). In higher plants, carotenoids are distributed between the two photosystems centres. In reaction centre of photosystem I carotenes and chlorophyll (maximum of absorbance at $\lambda=700 \mathrm{~nm}$ ) play a role, while xanthophylls and chlorophyll a (maximum of absorbance at $\lambda=680$ $\mathrm{nm}$ ) make up the majority of pigments in photosystem II (Demmig-Adams et al., 1996). Accordingly, at high insolation excess energy must be removed from the photosynthetic system to prevent damage. Carotenoid molecules are in close proximity to the chlorophyll molecules and quench the energetic triplet state of the chlorophyll molecules to prevent damage to the photosynthetic system (Miki, 1991, Frank \& Cogdell, 1996; Taiz \& Zeiger, 1998; Tracewell et al., 2001). Irradiance can affect increased accumulation of mineral and secondary plant metabolites (Havaux et al., 1998). Increases in photosynthesis, also will increase plant biomass (Mills \& Jones, 1996). An important class of secondary plant metabolites is the carotenoids. According to literature data, the content of carotenoids is less in plant leaves growing at shade conditions than in sunny place (Demmig-Adam et al., 1996). Similarly, in summer-grown kale leaves concerned more $\beta$-carotene than kale grown during winter months, when light levels are reduced (Azevedo \& Rodriguez-Amaya, 2005). However, the effect of solar irradiance on the production of carotenoid pigments is still unclear. That reason, the influence of UV radiation at the selected wave length $\lambda=254 \mathrm{~nm}$ (suitable to UVC solar radiation) was taken into consideration. Experiments were carried out for three cuttings of red and green kale. Even 4 hours per day of UV exposure brought about only insignificant damage of leaves. Finally, the concentration of lutein was $0.92 \pm 0.08$ $\mathrm{mg} / \mathrm{g}(0.90 \pm 0.08 \mathrm{mg} / \mathrm{g}$ by UV-VIS detection) for red kale and $0.28 \pm 0.02 \mathrm{mg} / \mathrm{g}(0.22 \pm 0.02 \mathrm{mg} / \mathrm{g}$ by UV-VIS detection) for green kale. In case of red kale this amount is about $75 \%$ higher than starting, but for green kale is less than in the beginning of experiments

Similar effects were observed for plants cultivated in saline stress (watering by use of $5 \% \mathrm{NaCl}$ solution). In this case we obtained $0.82 \pm 0.06 \mathrm{mg} / \mathrm{g}(0.79 \pm 0.08 \mathrm{mg} / \mathrm{g}$ by UV-VIS detection) and $0.13 \pm 0.08 \mathrm{mg} / \mathrm{g}(0.11 \pm 0.01$ $\mathrm{mg} / \mathrm{g}$ by UV-VIS detection) of lutein for red and green kale, respectively. The decrease in lutein concentration could be due to effects of its photodegradation as well as dilution of the concentration as plants grow. Moreover, obtained results show that kale is a rich source of lutein.

A higher concentration of lutein was observed in fully developed leaves of red kale than green kale. But red kale lutein content is not significantly different compared with green kale. We concluded that Redbor $\mathrm{F}_{1}$ kale is more biological resistant, than usually cultivated green leaf kale (Winterbor $\mathrm{F}_{1}$ ).

\section{Conclusions}

The differences in pigment ratios during cultivation of kale are related to environmental growing conditions. Obtained results show maximum xantophylls (lutein) concentrations in plants grow at range of air temperature 20 $-24^{\circ} \mathrm{C}$. Higher concentration of lutein occurs in red coloured kale leaves than green coloured. Red coloured kale is more resistant to saline stress growing conditions. The using of unprofitable cultivation conditions has effect in low concentration of lutein but also others carotenoids and chlorophylls.

Results obtained from the current study show maximum xantophylls (lutein) concentration occur in fully developed plant leaves of kale.

The quantitative analysis of lutein separated from kale extracts needs high performance liquid chromatography (HPLC) coupled with UV-VIS or mass spectrometry (MS) detectors. Especially, the determination of lutein by HPLC-MS in SIM mode allows to obtaining more reproducible results.

\section{Acknowledgements}

This work was supported by the Nicolaus Copernicus University grant (project no. 360-Ch).

This work was supported by CEEPUS Programme No. CII-RO-0313-01-0809-M-28147 and No. CII-RO-0313-01-0809-M-28150.

The authors wish to thank Andra A. Tomescu, Stefania Tanase (Faculty of Medicine, Transilvania University of Brasov, Brasov, Romania) and Łukasz Starosta (Chair of Environmental Chemistry and Bioanalytics, Faculty of Chemistry, Nicolaus Copernicus University, Torun, Poland) for their technical assistance.

\section{References}

Aehle, E., Raynaud-Le Grandic, S., Ralainirina, R., Baltora-Rosset, S., Mesnard, F., Prouillet, Ch., ... Fliniaux M. A. (2004). Development and evaluation of an enriched natural antioxidant preparation obtained from aqueous spinach (Spinacia oleracea) extracts by an adsorption procedure. Food Chemistry, 86, 579-585. http://dx.doi.org/10.1016/j.foodchem.2003.10.006 
Aman, R., Carle, R., Conrad, J., Beifuss, U., \& Schieber A. (2005). Isolation of carotenoids from plant materials and dietary supplements by high-speed counter-current chromatography. Journal of Chromatography A, 1074, 99-105. http://dx.doi.org/10.1016/j.chroma.2005.03.055

Aritomi, M., \& Kawasaki, T. (1984). Three highly oxygenated flavone glucuronides in leaves of Spinacia oleracea. Phytochemistry, 23, 2043-2047. http://dx.doi.org/10.1016/S0031-9422(00)84967-5

Cao, G., Sofic, E., \& Prior, R. L. (1996). Antioxidant capacity of tea and common vegetables. Journal of Agricultural and Food Chemistry, 44, 3426-3431. http://dx.doi.org/10.1021/jf9602535

de Azevedo, C. H., \& Rodriguez-Amaya, D. B. (2005). Carotenoid composition of kale as influenced by maturity, season and minimal processing. Journal of the Science of Food and Agriculture, 85, 591-597. http://dx.doi.org/10.1002/jsfa.1993

Decoteau, D. R. (2000)). Vegetable crops. Upper Saddle River, NJ, USA: Prentice-Hall, Inc.

Demmig-Adams, B., Gilmore, A. M., \& Adams, W. W. III. (1996). In vivo functions of carotenoids in higher plants. The FASEB Journal, 10, 403-412.

Edenharder, R., Keller, G., Platt, K. L., \& Unger, K. K. (2001). Isolation and Characterization of Structurally Novel Antimutagenic Flavonoids from Spinach (Spinacia oleracea) Journal of Agricultural Food Chemistry, 49, 2767-2773. http://dx.doi.org/10.1021/jf0013712

Frank, H. A., \& Cogdell, R. J. (1996). Carotenoids in photosynthesis. Photochemistry and Photobiology, 63, 257-264. http://dx.doi.org/10.1111/j.1751-1097.1996.tb03022.x

Gil, M. I., Ferreres, F., \& Tomas-Barberan, F. A. (1999). Effect of postharvest storage and processing on the antioxidant constituents (flavonoids and vitamin C) of fresh-cut spinach. Journal of Agricultural Food Chemistry, 47, 2213-2217. http://dx.doi.org/10.1021/jf9812001

Goldmann, I. L., Kader, A. A., \& Heintz, C. H. (1999). Influence of production, handling and storage on $\begin{array}{lllll}\text { phytonutrients contents in foods. Nutrition Reviews, 57, S46-S52. } & \text {. }\end{array}$ http://dx.doi.org/10.1111/j.1753-4887.1999.tb01807.x

Gross J. (1991). Pigments in vegetables: chlorophylls and carotenoids. New York, NY, USA: AVI/Van Nostrand Reinhold.

Grusak, M. A., DellPenna, D., \& Welch, R. M. (1999). Physiologic processes affecting the content and distribution of phytonutrients in plants. Nutrition Reviews, 57, S27-S33. http://dx.doi.org/10.1111/j.1753-4887.1999.tb01804.x

Handelman, G. J., Nightingale, Z. D., Lichtenstein, A. H., Schaefer, E. J., \& Blumberg, J. B. (1999). Lutein and zeaxanthin concentrations in plasma after dietary supplementation with egg yolk. The American Journal of Clinical Nutrition, 70, 247-251.

Holden, J. M., Eldridge, A. L., Beecher, G. R., Buzzard, I. M., Bhagwat, S., Davis, C. S., ... Schakel, S. (1999). Carotenoid content of U.S. foods: an update of the database. Journal of Food Composition and Analysis, 12, 169-196. http://dx.doi.org/10.1006/jfca.1999.0827

Jackson, H., Braun, C. L., \& Ernst, H. (2008). The chemistry of novel xanthophyll carotenoids. American Journal of Cardiology, 101, 50-57. http://dx.doi.org/10.1016/j.amjcard.2008.02.008

Kopsell, D. A., Kopsell, D. E., Lefsrud, M. G., Curran-Celentano, J., \& Dukach, L. E. (2004). Variation in Lutein, $\beta$-carotene, and Chlorophyll Concentrations among Brassica oleracea Cultigens and Seasons. HortScience, 39, 361-364.

Korus, A., \& Lisiewska, Z. (2011). Effect of preliminary processing and method of preservation on the content of selected antioxidative compounds in kale (Brassica oleracea L. var. acephala ) leaves. Food Chemistry, 129, 149-154. http://dx.doi.org/10.1016/j.foodchem.2011.04.048

Kurilich, A. C., Tsau, G. J., Brown, A., Howard, L., Klein, B. P., Jeffery, E. H., ... Juvik, J. A. (1999). Carotene, tocopherol, and ascorbate in subspecies of Brassica oleracea. Journal of Agricultural Food Chemistry, 47, 1576-1581. http://dx.doi.org/10.1021/jf9810158

Landrum, J. T., \& Bone, R. A. (2001). Lutein, zeaxanthin, and the macular pigment. Archives of Biochemistry and Biophysics, 385, 28-40. http://dx.doi.org/10.1006/abbi.2000.2171 
Lefsrud, M., Kopsell, D., Wenzel, A., \& Sheehan, J. (2007). Changes in kale (Brassica oleracea L. var. acephala) carotenoid and chlorophyll pigment concentrations during leaf ontogeny. Scientia Horticulturae, 112, 136-141. http://dx.doi.org/10.1016/j.scienta.2006.12.026

Lefsrud, M. G., Kopsell, D. A., Kopsell, D. E., \& Curran-Celentano J. (2005). Air temperature affects biomass and carotenoid pigment accumulation in kale and spinach grown in a controlled environment. HortScience, 40, 2026-2030.

Lefsrud, M. G., Kopsell, D. A., Kopsell, D. E., \& Curran-Celentano, J. (2006). Irradiance levels affect growth parameters and carotenoid pigments in kale and spinach grown in a controlled environment. Physiologia Plantarum, 127, 624-631. http://dx.doi.org/10.1111/j.1399-3054.2006.00692.x

Lin, J. Y., \& Tang, Ch. Y. (2007). Determination of total phenolic and flavonoid contents in selected fruits and vegetables, as well as their stimulatory effects on mouse splenocyte proliferation. Food Chemistry, 101, 140-147. http://dx.doi.org/10.1016/j.foodchem.2006.01.014

Loane, E., Nolan, J. M., O’Donovan, O., Bhosale, P., Bernstein, P. S., \& Beatty, S. (2008). Transport and retinal capture of lutein and zeaxanthin with reference to age-related macular degeneration. Survey of Ophthalmology, 53, 68-81. http://dx.doi.org/10.1016/j.survophthal.2007.10.008

Lomnitski, L., Carbonatto, M., Ben-Shaul, V., Peano, S., Conz, A., Corradin, L., ... Nyska, A. (2000). The prophylactic effects of natural water-soluble antioxidant from spinach and apocynin in a rabbit model of lipopolysaccharide-induced endotoxemia. Toxicologic Pathology, 28, 588-600. http://dx.doi.org/10.1177/019262330002800413

Miki, W. (1991). Biological functions and activities of animal carotenoids. Pure Applied Chemistry, 63, 141-146. http://dx.doi.org/10.1351/pac199163010141

Mills, H. A., \& Jones, J. B. Jr. (1996). Plant Analysis Handbook II: A Practical Sampling, Preparation, Analysis, and Interpretation Guide. MicroMacro Publishing, Athens, GA.

Mozaffarieh, M., Sacu, S., \& Wedrich, A. (2003). The role of the carotenoids, lutein and zeaxanthin, in protecting against age-related macular degeneration: A review based on controversial evidence. Nutrition Journal, 2, 20-28. http://dx.doi.org/10.1186/1475-2891-2-20

Paul, N. K. (1991). Influence of temperature on leaf area development in Brassica species. Bangladesh Journal of Botany, 20, 143-148.

Quach, H. T., Steeper, R. L., \& Griffin, G. W. (2004). An improved method for the extraction and thin-layer chromatography of chlorophyll and from spinach. Journal of Chemical Education, 81, 385-387. http://dx.doi.org/10.1021/ed081p385

Rao, A. V., \& Rao, L. G. (2007). Carotenoid and human health. Pharmacology Research, 55, 207-216. http://dx.doi.org/10.1016/j.phrs.2007.01.012

Ribaya-Mercado, J. D., \& Blumberg, J. B. (2004). Lutein and zeaxanthin and their potential roles in disease prevention. Journal of the American College of Nutrition, 23, 567S-587S.

Roberts, R. L., Green, J., Lewis, B. (2009). Lutein and zeaxanthin in eye and skin health. Clinics in Dermatology, 27, 195-201. http://dx.doi.org/10.1016/j.clindermatol.2008.01.011

Rock, C. L. (1997). Carotenoids: biology and treatment. Pharmacology \& Therapeutics, 75, 185-197. http://dx.doi.org/10.1016/S0163-7258(97)00054-5

Sikora, E., Cieślik, E., Leszczyńska, T., Filipiak-Florkiewicz, A., \& Pisulewski, P. (2008). The antioxidant activity of selected cruciferous vegetables subjected to aquathermal processing. Food Chemistry, 107, 55-59. http://dx.doi.org/10.1016/j.foodchem.2007.07.023

Sommerburg, O., Keunen, J. E. E., Bird, A. C., \& van Kuijk, F. J. G. M. (1998). Fruits and vegetables that are sources for lutein and zeaxanthin: the macular pigment in human eyes. British Journal of Ophthalmology, 82, 907-910. http://dx.doi.org/10.1136/bjo.82.8.907

Taiz, L., \& Zeiger, E. (1998). Plant Physiology, 2nd edn. Sinauer Associates Inc., Sunderland, MA, USA.

Tracewell, C. A., Vrettos, J. S., Bautista, J. A., Frank, H. A., \& Brudvig, G. W. (2001). Carotenoid photooxidation in photosystem II. Archives of Biochemistry and Biophysics, 385, 61-69. http://dx.doi.org/10.1006/abbi.2000.2150 
Tsao, R., Yang, R., Young, J. Ch., Zhua, H., \& Manolis, T. (2004). Separation of geometric isomers of native lutein diesters in marigold (Tagetes erecta L.) by high-performance liquid chromatography-mass spectrometry. Journal of Chromatography A, 1045, 65-70. http://dx.doi.org/10.1016/j.chroma.2004.06.020

Tyssandier, V., Cardinault, N., Caris-Veyrat, C., Amiot, M. J., Grolier, P., Bouteloup, C., Azais-Braesco, V., \& Borel, P. (2002). Vegetable-borne lutein, lycopene, and $\beta$-carotene compete for incorporation into chylomicrons, with no adverse effect on the medium-term (3-wk) plasma status of carotenoids in humans. The American Journal of Clinical Nutrition, 75, 526-534.

Voutilainen, S., Nurmi, T., Mursu, J., \& Rissanen, T. H. (2006). Carotenoids and cardiovascular health. The American Journal of Clinical Nutrition, 83, 1265-1271.

Wood, R. (1988). The Whole Foods Encyklopedia. New York, NY, USA: Prentice-Hall Press.

Wright, C. A. (2001). Mediterranean Vegetables: A Cook's ABC of Vegetables and their Preparation in Spain, France, Italy, Greece, Turkey, the Middle East, and North Africa, with More than 200 Authentic Recipes for the Home Cook. Boston, MA, USA: Harvard Common Press. 